INTERVENTIONAL CARDIOLOGY AND SURGERY

\title{
Mechanism of improvement in exercise capacity after the maze procedure combined with mitral valve surgery
}

\author{
S Yuda, S Nakatani, Y Kosakai, T Satoh, Y Goto, M Yamagishi, K Bando, S Kitamura, K Miyatake
}

Heart 2004;90:64-69

See end of article for authors' affiliations

Correspondence to:

Dr S Nakatani, Division of Cardiology, National Cardiovascular Centre, 5-

7-1 Fujishiro-dai, Suita, Osaka 565-8565, Japan; nakatas@hsp.ncvc.go.jp

Accepted 4 July 2003

\begin{abstract}
Objective: To clarify the mechanism of improvement in exercise capacity after the maze procedure. Design: Retrospective study.

Setting: Tertiary referral centre.

Patients: 26 patients (mean (SD) age 57 (9) years) with atrial fibrillation (AF) and mitral valve disease were studied with echocardiography and cardiopulmonary exercise testing before and after the maze procedure combined with mitral valve surgery. Of these, eight had persistent AF and 18 had restored sinus rhythm (SR) by the surgery. Six patients (mean (SD) age 59 (12) years) with AF undergoing mitral valve surgery without the maze procedure who had cardiopulmonary exercise testing before and after the surgery formed the control group.

Main outcome measures: Echocardiographic parameters of atrial function were measured from transmitral flow recordings. Peak oxygen uptake $\left(\mathrm{V}_{2}\right)$ and the slope of the relation between $\dot{\mathrm{V}}_{2}$ and workload (ratio of $\Delta \mathrm{VO}_{2}$ to $\Delta$ work) were determined as indices of exercise capacity.

Results: The degree of improvements in peak $\dot{\mathrm{V}}_{2}$ and the ratio of $\Delta \dot{\mathrm{V}}_{2}$ to $\Delta$ work after the mitral valve surgery was comparable between the maze and control group. It was also comparable between patients with and those without successfully restored SR after the maze procedure. The degree of the increase in peak $\dot{V}_{2}$ correlated with the change in left atrial diameter $(r=-0.40, p=0.047)$ but atrial contraction did not correlate with the increase.

Conclusions: Improvement in exercise capacity may not be caused by restored SR and atrial contraction but may at least partly relate to the reduction of left atrial size and improvement of haemodynamic variables by the surgery.
\end{abstract}

$\mathrm{g}$ mproved postoperative exercise capacity in patients undergoing mitral valve surgery has been reported to depend on several factors such as sex, preoperative functional status, persistence of pulmonary hypertension, right ventricular function, physical training, and improvement in ventilatory function. ${ }^{1-7}$ Skeletal muscle structure and metabolism have also been shown to be associated with exercise capacity in patients with mitral stenosis who have undergone balloon mitral valvoplasty. ${ }^{89}$ Although postoperative rhythm is expected to have an important role in the recovery of exercise capacity, surprisingly little data are available about this issue. Atrial fibrillation (AF) is a common arrhythmia and is well known to impair the exercise capacity of patients with mitral valve disease. ${ }^{10}$ However, there has been only limited information regarding the effect of $\mathrm{AF}$ or the effect of restored sinus rhythm (SR) on the degree of postoperative improvement in exercise capacity after mitral valve surgery. ${ }^{311}$

The maze procedure, originally developed by Cox and colleagues $^{12}$ and later modified by Kosakai and colleagues, ${ }^{13}$ has been shown to be a safe and effective treatment for refractory $\mathrm{AF}$ associated with mitral valve disease. ${ }^{13-15}$ We have recently shown that the restored SR and atrial contraction were maintained for a long time in patients with mitral valve disease. ${ }^{16}$ The exercise capacity of patients with ${ }^{17}{ }^{18}$ and without ${ }^{19}$ organic heart disease who underwent the maze procedure has been reported to improve in the late phase. However, most patients in previous studies recovered from $\mathrm{AF}$ and no reports have focused on the exercise capacity of patients with persistent AF after the maze procedure. Thus, it is unknown to what extent this improvement is related to restored SR and atrial contraction after the procedure. In the present study, we sought to clarify the mechanism of improvement in exercise capacity after the maze procedure combined with mitral valve surgery.

\section{METHODS}

\section{Patients' characteristics}

Sixty six patients had received cardiac surgery with the maze procedure and cardiopulmonary exercise testing before $(<6$ months) the surgery between July 1992 and May 1996. Of these, 37 patients who had no cardiopulmonary exercise testing after the surgery were excluded. Further, we excluded three patients who underwent cardiopulmonary exercise testing during the early postoperative phase ( $<6$ months) because we considered only exercise capacity that improved late after maze surgery. ${ }^{17}$ The remaining 26 patients formed the maze group. All patients in the maze group had mitral valve diseases and chronic AF defined as AF lasting $>6$ months (mean (SD) duration 7.6 (7.2) years, range 0.5-30 years). Eighteen patients had SR at the time of follow up cardiopulmonary exercise testing (maze-SR group: 10 men, age 59 (8) years, range 37-69 years) and eight patients had persistent AF (maze-AF group: five men, mean (SD) age 54 (9) years, range 46-72 years) after the surgery. Seven patients had mitral stenosis, eight had mitral regurgitation, nine had both mitral stenosis and regurgitation, and two had prosthetic mitral valve failure. The modified maze procedure was performed simultaneously with mitral valve surgery ( $n=26)$, aortic valve surgery $(n=9)$, tricuspid annuloplasty $(\mathrm{n}=9)$, and left atrial (LA) plication $(\mathrm{n}=1)$. Age,

Abbreviations: $A F$, atrial fibrillation; $L A$, left atrial; $L V$, left ventricular; $\mathrm{SR}$, sinus rhythm; $\mathrm{VO}_{2}$, oxygen uptake 
mitral valve disease, additional procedure, New York Heart Association functional class, and preoperative and postoperative medication were not significantly different between the maze-SR and maze-AF groups, but the duration of AF was significantly longer in the maze-AF group. The New York Heart Association functional class in patients undergoing the maze procedure improved significantly after the surgery (table 1). Only one patient underwent programmed rehabilitation after the surgery.

During the same time period, six patients (three men, mean age 59 (12) years, range 44-73 years) with AF had cardiopulmonary exercise testing before and after the surgery without maze procedure and they served as the control group. The duration of $\mathrm{AF}$ in the control group was significantly longer than that in the maze group (table 1).

\section{Maze procedure}

We have modified the maze procedure originated by Cox and colleagues. ${ }^{12}$ Details of the procedure we performed have been previously reported. ${ }^{13}$ The major modifications are changes in atriotomy lines, aimed at preserving the sinus node arteries, and use of cryoablation instead of atriotomy and reanastomosis to simplify the procedure. Other modifications are transection of the superior vena cava and detachment of the left ventricle at the circumferential left atriotomy around the pulmonary veins to improve exposure and manipulation of the mitral valve.

\section{ECG}

A standard 12 lead ECG was recorded from all patients at their regular visit to our hospital, which was a month after discharge, and the cardiac rhythm was determined.

\section{Ultrasound examination}

Ultrasound examinations were performed with a commercially available ultrasound system (SSD 870, Aloka, Tokyo, Japan; SSH-160A, Toshiba, Tokyo, Japan; or SONOS 2000, Hewlett Packard, Andover, Massachusetts, USA) with a $2.5 \mathrm{MHz}$ imaging transducer before (mean (SD) 1.7 (2.5) months) and after (16.8 (13.4) months) the surgery. LA diameter and left ventricular (LV) end diastolic and end systolic diameters were determined from M mode or B mode echocardiogram and LV fractional shortening was obtained.

Transmitral flow velocity was measured with pulsed Doppler echocardiography by positioning a sample volume at the level of the mitral tip in the apical four chamber view and was recorded on a strip chart at a paper speed of $100 \mathrm{~mm} / \mathrm{s}$. Peak velocity and the time-velocity integral of the late filling wave (A wave) were determined. ${ }^{16} 20$ When the deceleration line of the early filling wave did not reach the baseline, the time-velocity integral of the A wave was measured as an area above the extrapolation line of early filling wave deceleration. The atrial filling fraction was derived as the ratio of the time-velocity integral of the A wave to that of total diastolic filling. Each measurement was

Table 1 Clinical characteristics of 32 patients with atrial fibrillation associated with mitral valve disease

\begin{tabular}{|c|c|c|c|c|c|c|c|c|c|c|}
\hline \multirow{2}{*}{$\begin{array}{l}\text { Patient } \\
\text { number }\end{array}$} & \multirow{2}{*}{$\begin{array}{l}\text { Rhythm after } \\
\text { surgery }\end{array}$} & \multirow{2}{*}{$\begin{array}{l}\text { Age } \\
\text { (years) }\end{array}$} & \multirow[b]{2}{*}{ Sex } & \multirow{2}{*}{$\begin{array}{l}\text { AF duration } \\
\text { (years) }\end{array}$} & \multirow[b]{2}{*}{ Diagnosis } & \multirow[b]{2}{*}{ Procedures } & \multicolumn{2}{|c|}{ NYHA class } & \multicolumn{2}{|l|}{ Medications } \\
\hline & & & & & & & Before & After* & Before & After \\
\hline \multicolumn{11}{|c|}{ Maze group } \\
\hline 1 & SR & 37 & $M$ & 1.4 & $M R, A R$ & MVP,AVP & I & I & $\mathrm{D}, \mathrm{DI}$ & $A, C, D$ \\
\hline 2 & SR & 64 & $M$ & 1.2 & PVF & Re-MVR & ॥ & I & $\mathrm{A}, \mathrm{DI}$ & - \\
\hline 3 & SR & 59 & $M$ & 1.4 & MSR & MVP,TAP & ॥ & I & DI & $A, D I$ \\
\hline 4 & SR & 52 & M & 4.9 & MSR & MVR & $\|$ & $\|$ & $A, D, D I$ & $A, D$ \\
\hline 5 & SR & 68 & $\mathrm{~F}$ & 3.3 & MSR & MVP,TAP & III & $\|$ & $C, D, D I$ & $D, D I$ \\
\hline 6 & SR & 61 & $\mathrm{~F}$ & 3.6 & MR & MVR & ॥ & I & $\mathrm{A}, \mathrm{DI}$ & - \\
\hline 7 & SR & 51 & $\mathrm{~F}$ & 1.3 & MSR,ASR & MVR,AVR & ॥ & i & $\mathrm{D}, \mathrm{DI}$ & $D, D I$ \\
\hline 8 & SR & 59 & $\mathrm{~F}$ & 5.9 & MSR & MVR,TAP & III & i & $A C, D, D I$ & $D, D I$ \\
\hline 9 & SR & 59 & $\mathrm{~F}$ & 4 & MSR,ASR & MVP,AVP & $\|$ & III & $\mathrm{D}, \mathrm{DI}$ & $A, D, D I$ \\
\hline 10 & SR & 69 & $M$ & 1.6 & $M R, A R$ & MVP,AVP & $\|$ & $\|$ & $D, D I$ & $A, C, D, D I$ \\
\hline 11 & SR & 50 & M & 3 & MS & MVP & I & I & $\mathrm{C}, \mathrm{DI}$ & $\mathrm{A}, \mathrm{DI}$ \\
\hline 12 & SR & 57 & M & 5.9 & MS,AS & MVP,AVR & $\|$ & I & $D, D I$ & $A, D$ \\
\hline 13 & SR & 60 & M & 4.1 & $M S, A R$ & MVR,AVP & II & i & $C, D, D I$ & $A, D$ \\
\hline 14 & SR & 68 & M & 0.5 & MR & MVP,TAP & $\|$ & i & $A C, D, D I$ & $A C, D$ \\
\hline 15 & SR & 60 & $\mathrm{~F}$ & 13 & MR & MVR,TAP & ॥ & I & $\mathrm{D}, \mathrm{DI}$ & $A, D, D I$ \\
\hline 16 & SR & 52 & $\mathrm{~F}$ & 2.7 & MS & MVP,TAP & II & i & $A, D$ & $A, D, D I$ \\
\hline 17 & SR & 66 & $\mathrm{~F}$ & 13 & MS & MVR & II & II & $A, D, D I$ & $A, D I$ \\
\hline 18 & SR & 69 & $M$ & 30 & MSR,AR & MVR,AVR,TAP & II & i & $A C, D, D I$ & $A C, D, D I$ \\
\hline 19 & $\mathrm{AF}$ & 57 & M & 20 & MR & MVP & ॥ & i & $A, A C, D, D I$ & $A, D, D I$ \\
\hline 20 & $\mathrm{AF}$ & 47 & $\mathrm{~F}$ & 12 & PVF & Re-MVR,TAP & ॥ & I & $D, D I$ & $A, D$ \\
\hline 21 & $\mathrm{AF}$ & 58 & $\mathrm{~F}$ & 15 & $M S, A R$ & $M V P, A V P$ & $\|$ & $\|$ & $\mathrm{D}, \mathrm{DI}$ & D \\
\hline 22 & $\mathrm{AF}$ & 46 & $M$ & 10 & $M S, A R$ & MVR,AVR & I & I & $\mathrm{D}, \mathrm{DI}$ & $D, D I$ \\
\hline 23 & $\mathrm{AF}$ & 50 & M & 15 & MSR & MVR,LAP & III & i & C,DI & $C, \mathrm{DI}$ \\
\hline 24 & $\mathrm{AF}$ & 53 & $\mathrm{~F}$ & 14 & MSR & MVR & $\|$ & i & $A C, D, D I$ & $\mathrm{D}, \mathrm{DI}$ \\
\hline 25 & $\mathrm{AF}$ & 48 & M & 9.5 & MR & MVP,TAP & II & I & $A C, D I$ & $A, D I$ \\
\hline 26 & $\mathrm{AF}$ & $\begin{array}{l}72 \\
57(9)\end{array}$ & $M$ & $\begin{array}{l}0.5 \\
7.6(7.2)\end{array}$ & MR & MVR & II & i & $A C, C, D, D I$ & $C, D, D I$ \\
\hline \multicolumn{11}{|c|}{ Control group } \\
\hline 1 & $\mathrm{AF}$ & 50 & $M$ & 18 & MS & MVR,TAP & $\|$ & I & $A C, D, D I$ & $A C, D, D I$ \\
\hline 2 & $\mathrm{AF}$ & 58 & $\mathrm{~F}$ & 20 & MSR & MVR,TAP & II & I & $D, D I$ & $D, D I$ \\
\hline 3 & $\mathrm{AF}$ & 72 & M & 12 & $M R, A R$ & MVR,AVR & III & $\|$ & $\mathrm{D}, \mathrm{DI}$ & $A, D I$ \\
\hline 4 & $\mathrm{AF}$ & 57 & $M$ & 31 & MS & MVR,TAP,LAP & I & 1 & $C, D, D I$ & $D, D I$ \\
\hline 5 & $\mathrm{AF}$ & 73 & $\mathrm{~F}$ & 10 & PVF & Re-MVR & II & i & $A C, D I$ & $A C, D, D I$ \\
\hline 6 & $\mathrm{AF}$ & 44 & $\mathrm{~F}$ & 18 & PVF & Re-MVR & $\|$ & i & $\mathrm{DI}$ & $\mathrm{D}, \mathrm{DI}$ \\
\hline
\end{tabular}

Data are mean (SD). ${ }^{*} p<0.01 v$ before in maze group; ${ }^{* *} p<0.01 v$ maze group.

$A$, antiarrhythmic drugs; $A C$, angiotensin converting enzyme inhibitors; $A F$, atrial fibrillation; $A R$, aortic regurgitation; $A S$, aortic stenosis; $A S R$, aortic stenosis and regurgitation; $A V P$, aortic valvoplasty; $A V R$, aortic valve replacement; $C$, calcium antagonists; $D$, diuretics; $D I$, digitalis; $F$, female; LAP, left atrial plication; $M$, male; MR, mitral regurgitation; MS, mitral stenosis; MSR, mitral stenosis and regurgitation; MVP, mitral valvoplasty; MVR, mitral valve replacement; NYHA, New York Heart Association; PVF, prosthetic valve failure; Re, reoperation; SR, sinus rhythm; TAP, tricuspid annuloplasty. 
obtained as an average of 6-8 consecutive beats. We arbitrarily considered an A wave peak velocity $\geqslant 10 \mathrm{~cm} / \mathrm{s}$ to be echocardiographic evidence of effective atrial contraction. ${ }^{16}{ }^{20}$ The right ventriculoatrial peak pressure gradient was calculated by applying the simplified Bernoulli equation to the tricuspid regurgitation velocity measured by continuous wave Doppler echocardiography. We considered a peak pressure gradient $>25 \mathrm{~mm} \mathrm{Hg}$ to indicate pulmonary hypertension..$^{21}$ Data were analysed by a person (SY) blinded to all clinical and patient information.

\section{Cardiopulmonary exercise testing}

All patients underwent cardiopulmonary exercise testing on an upright bicycle ergometer before (2.6 (2.6) months) and after (16.3 (9.3) months) surgery. They first pedalled at $55 \mathrm{rpm}$ with no added load for one minute. The work rate was then increased by $15 \mathrm{~W} / \mathrm{min}$ up to the patient's symptom limited maximum exercise level. Breath by breath gas was analysed with an AE-280 spiroergometer (Minato Medical Science Co, Osaka, Japan) connected to a personal computer running analysing software. Peak oxygen uptake $\left(\dot{\mathrm{V}}_{2}\right)$ was determined as the value of the averaged data during the final $15 \mathrm{~s}$ of exercise. The ratio of change in $\dot{\mathrm{VO}}_{2}$ to change in work rate (ratio of $\Delta \dot{\mathrm{V}}_{2}$ to $\Delta$ work) was calculated as the slope of $\dot{\mathrm{V}}_{2}$ per unit workload from one minute after the start of load addition until $85 \%$ maximum $\dot{\mathrm{V}}_{2} .{ }^{22}$ During the exercise test, heart rate was continuously monitored and blood pressure was measured with a sphygmomanometer every minute.

\section{Statistical analysis}

All data are expressed as mean (SD). Continuous variables were compared with Student's paired or unpaired $t$ test as appropriate and the three groups were compared by analysis of variance with the Scheffé post hoc test. Linear regression analysis was used to identify the correlation between the change in peak $\dot{\mathrm{V}}_{2}$ or $\Delta \dot{\mathrm{V}}_{2}$ to $\Delta$ work ratio and echocardiographic parameters. Categorical variables were analysed with the $\chi^{2}$ test and Fisher's exact test was used when appropriate. We considered results significant when $\mathrm{p}<0.05$.

\section{RESULTS \\ ECG findings}

In the maze group, SR was noted in 17 of the 26 patients $(65 \%)$ on ECG one month after surgery. In the remaining nine patients, SR was restored in one patient two months after surgery and AF persisted in eight $(31 \%)$. Once SR was restored no patient reverted to AF. No patient in the control group had restored SR after surgery.

\section{Ultrasound parameters}

LA diameter in the maze-SR group and LV end diastolic diameter in the maze-AF group decreased significantly after the surgery. Right ventriculoatrial peak pressure gradient in the control group and the incidence of tricuspid regurgitation in the maze-SR group decreased significantly after the surgery. LV fractional shortening and LA and LV end diastolic diameters did not differ between the maze-AF and maze-SR groups both before and after the surgery (table 2 ).

Three patients had residual severe mitral regurgitation and two had residual severe tricuspid regurgitation. No patients had significant obstructive prosthetic mitral valve failure (3.4 (0.3) $\mathrm{mm} \mathrm{Hg}$ for peak diastolic pressure gradient and 1.4 (0.8) $\mathrm{mm} \mathrm{Hg}$ for mean diastolic pressure gradient) after the surgery. Ten patients $(56 \%)$ in the maze-SR group had effective atrial contraction, as shown by a restored Doppler transmitral A wave $(\geqslant 10 \mathrm{~cm} / \mathrm{s})$. The mean A wave peak velocities, time-velocity integrals, and atrial filling fractions were $51(23) \mathrm{cm} / \mathrm{s}, 4(2) \mathrm{cm}$, and $15(4) \%$, respectively.

\section{Exercise testing parameters}

The mean time intervals from the surgery to cardiopulmonary exercise testing did not differ between the maze-SR, maze$\mathrm{AF}$, and control groups (14.6 (6.6) v 19.1 (9.3) v 17.4 (15.5) months, respectively, $\mathrm{p}=0.48$ ). Maximum work load was similar in the three groups before and after surgery but increased significantly after surgery in the maze-SR group. Heart rate at rest before and after surgery and peak heart rate before surgery did not differ between the three groups, but peak heart rate in the maze-SR group decreased significantly after surgery. Systolic blood pressure at rest and peak in the maze-SR group and that at peak in the maze-AF group increased significantly after the surgery. Maximum work load, heart rate, and systolic blood pressure at rest or peak did not differ between the maze-AF and maze-SR groups both before and after surgery, except for the peak heart rate (table 2).

Peak $\dot{\mathrm{VO}}_{2}$ did not differ between the three groups before surgery and it increased similarly in all groups (33.1 (46.1)\% $v 15.6(25.2) \% v 22.1(17.8) \%$ for the maze-AF, maze-SR, and control group, respectively, $\mathrm{p}=0.54$ ) (fig l, left panel). $\Delta \dot{\mathrm{V}}_{2}$ to $\Delta$ work ratio also did not differ between the three groups before surgery. It also increased in the all groups after the surgery (fig 1, right panel).

Since the surgical procedure itself may influence exercise capacity, we determined it by the procedure. In the maze group, peak $\dot{\mathrm{V}}_{2}$ in patients with mitral valve replacement $(\mathrm{n}=12)$ increased significantly after surgery (from 17.5 (4.1) $\mathrm{ml} / \mathrm{kg} / \mathrm{min}$ to $21.3(4.7) \mathrm{ml} / \mathrm{kg} / \mathrm{min}, \mathrm{p}=0.023$ ) but not in those with mitral valve repair $(\mathrm{n}=12$, from 18.6 (4.9) $\mathrm{ml} / \mathrm{kg} / \mathrm{min}$ to $20.2 \quad$ (5.7) $\mathrm{ml} / \mathrm{kg} / \mathrm{min}, \quad \mathrm{p}=0.19$ ). Further, no significant increase was found in patients with residual severe mitral or tricuspid regurgitation after surgery (from $17.0 \quad(4.3) \mathrm{ml} / \mathrm{kg} / \mathrm{min}$ to $17.7 \quad$ (3.2) $\mathrm{ml} / \mathrm{kg} / \mathrm{min}$, $\mathrm{p}=0.70)$.

Of the 18 patients with restored SR, peak $\dot{\mathrm{V}}_{2}(21.9$ (6.0) $v$ 18.7 (3.6) $\mathrm{ml} / \mathrm{kg} / \mathrm{min}, \mathrm{p}=0.20$ ) and $\Delta \dot{\mathrm{V}}_{2}$ to $\Delta$ work ratio (7.6 (1.3) $\vee 7.8(1.1) \mathrm{ml} / \mathrm{kg} / \mathrm{min} / \mathrm{W}, \mathrm{p}=0.73)$ were not significantly different between patients with $(\mathrm{n}=10)$ and those without $(n=8)$ effective atrial contraction after the surgery. Further, A wave peak velocities, time-velocity integrals, and atrial filling fractions did not correlate with increase in peak $\dot{\mathrm{V}}_{2}(\mathrm{p}=0.50, \mathrm{p}=0.17$, and $\mathrm{p}=0.27$, respectively) and $\Delta \dot{\mathrm{V}}_{2}$ to $\Delta$ work ratio $(\mathrm{p}=0.78, \mathrm{p}=0.65$, and $\mathrm{p}=0.90$, respectively).

In the maze group, a decrease in LA diameter induced by the maze procedure combined with mitral valve surgery was significantly correlated with increase in peak $\dot{\mathrm{V}}_{2}$ $(r=-0.40, \mathrm{p}=0.047)$ (fig 2$)$ and tended to correlate with increase in $\Delta \dot{\mathrm{V}}_{2}$ to $\Delta$ work ratio $(r=-0.39, \mathrm{p}=0.059)$. However, age, duration of AF, and differences in peak heart rate, LV fractional shortening, LV end diastolic diameter, and right ventriculoatrial peak pressure gradient caused by the surgery did not correlate with increases in peak $\dot{\mathrm{V}}_{2}$ or $\Delta \dot{\mathrm{V}}_{2}$ to $\Delta$ work ratio.

\section{DISCUSSION}

We assessed the exercise capacity of patients who underwent mitral valve surgery with and without the maze procedure. Improvement in exercise capacity after the surgery was comparable between the maze and control group. It was also comparable between patients with and those without successfully restored SR after the maze procedure. The increase in peak $\dot{\mathrm{V}}_{2}$ correlated not with the postoperative restored atrial function but with the reduction of LA diameter. Reduction of LA size, not restored SR and atrial contraction, may be an important factor influencing exercise capacity after mitral valve surgery. 
Table 2 Echocardiography and cardiopulmonary exercise testing data of the study groups

\begin{tabular}{|c|c|c|c|c|c|c|c|}
\hline & \multicolumn{4}{|l|}{ Before surgery } & \multicolumn{3}{|l|}{ After surgery } \\
\hline & $\begin{array}{l}\text { Control group } \\
(n=6)\end{array}$ & $\begin{array}{l}\text { Maze-SR group } \\
(\mathrm{n}=18)\end{array}$ & $\begin{array}{l}\text { Maze-AF group } \\
(n=8)\end{array}$ & p Value & $\begin{array}{l}\text { Control group } \\
(n=6)\end{array}$ & $\begin{array}{l}\text { Maze-SR group } \\
(n=18)\end{array}$ & $\begin{array}{l}\text { Maze-AF group } \\
(\mathrm{n}=8)\end{array}$ \\
\hline \multicolumn{8}{|l|}{ Echocardiography } \\
\hline Left atrial diameter (mm) & $71.8(12.9)$ & $56.1(8.4)^{*}$ & $60.3(14.0)$ & 0.026 & $61.5(4.9)$ & $48.9(7.7)^{*} \ddagger$ & $49.9(7.7)^{*}$ \\
\hline LVEDD (mm) & $55.4(9.1)$ & $51.4(9.8)$ & $59.3(10.4)$ & 0.18 & $52.2(8.5)$ & $47.4(6.7)$ & $48.9(3.7) \dagger$ \\
\hline Fractional shortening (\%) & $31.1(8.5)$ & $33.4(8.5)$ & $33.2(7.0)$ & 0.85 & $30.3(12.1)$ & $33.6(6.8)$ & $32.3(8.6)$ \\
\hline Tricuspid regurgitation & $6(100 \%)$ & $17(94 \%)$ & $6(75 \%)$ & 0.20 & $6(100 \%)$ & $11(61 \%) \dagger$ & $7(88 \%)$ \\
\hline RVPG $(m m ~ H g)$ & $\begin{array}{l}39.3(13.6) \\
(n=6)\end{array}$ & $\begin{array}{l}29.8(12) \\
(n=16)\end{array}$ & $\begin{array}{l}28.5(8.0) \\
(n=6)\end{array}$ & 0.20 & $\begin{array}{l}28.8(13.2) \\
(n=6) \dagger\end{array}$ & $\begin{array}{l}27.1(10.0) \\
(n=9)\end{array}$ & $\begin{array}{l}23.8(6.1) \\
(n=6)\end{array}$ \\
\hline $\begin{array}{l}\mathrm{RVPG}>25 \mathrm{~mm} \mathrm{Hg} \\
\text { Cardiopulmonary exercise testing }\end{array}$ & $5(83 \%)$ & $8(44 \%)$ & $2(25 \%)$ & 0.09 & $2(33 \%)$ & $4(22 \%)$ & $2(25 \%)$ \\
\hline Maximum work load (w) & $94(26)$ & $101(30)$ & $96(27)$ & 0.84 & $95(41)$ & 117 (39)‡ & $112(31)$ \\
\hline Heart rate at rest (beats/min) & $78(15)$ & $88(15)$ & $89(15)$ & 0.33 & $73(14)$ & $83(16)$ & 85 (17) \\
\hline Heart rate at peak (beats/min) & $168(25)$ & $182(24)$ & $175(21)$ & 0.43 & $135(47)$ & 138 (17)‡ & $159(23)$ \\
\hline Systolic BP at rest $(\mathrm{mm} \mathrm{Hg})$ & $127(11)$ & $132(21)$ & $120(13)$ & 0.30 & $128(18)$ & $142(32) \dagger$ & $136(18)$ \\
\hline Systolic BP at peak (mm Hg) & $176(24)$ & $172(25)$ & $171(21)$ & 0.92 & 169 (33) & $200(34) \ddagger$ & $197(25) \dagger$ \\
\hline
\end{tabular}

\section{Comparison with previous studies}

We found that improved peak $\dot{\mathrm{V}}_{2}$ after the maze procedure combined with mitral valve surgery agreed with previous studies. ${ }^{17}{ }^{18}$ The $\Delta \dot{\mathrm{V}}_{2}$ to $\Delta$ work ratio, which indicates oxygen transport to the working muscles and has been considered to reflect cardiac output, ${ }^{22}$ also increased after surgery, as in a previous study. ${ }^{17}$ One of the limitations of those previous studies $^{17}{ }^{18}$ may be the lack of a control group (that is, patients with AF undergoing mitral valve surgery without the maze procedure). We found that the improvement in exercise capacity after mitral valve surgery was comparable between the group with and that without the maze procedure. Furthermore, residual mitral or tricuspid regurgitation was identified as a factor influencing exercise capacity after surgery.

The importance of restored SR and atrial contraction in the exercise capacity after mitral valve surgery has not been defined clearly. Triposkiadis and colleagues ${ }^{3}$ found a greater improvement in exercise capacity following mitral valve replacement for mitral stenosis in patients with SR than in those with AF. Tamai and colleagues ${ }^{11}$ found that exercise capacity following both balloon mitral valvoplasty and cardioversion for mitral stenosis increased significantly in patients with restored SR but not in those with persistent AF. Further, they have shown a significant correlation between the degree of improvement in peak $\dot{\mathrm{V}}_{2}$ and restored atrial function. ${ }^{11}$ In contrast, Deneke and colleagues ${ }^{23}$ showed in a randomised study that exercise capacity was not different between patients with mitral valve replacement combined with the maze procedure in which radiofrequency ablation was used and those with mitral valve replacement alone, which is consistent with our findings. The inconsistent findings may be explained by differences in the patients' characteristics such as mitral stenosis or regurgitation and depressed atrial function after the maze procedure. ${ }^{16}$

Restored SR and atrial contraction by the maze procedure seemed not to play such an important part in exercise capacity. However, we found that maximal work load increased significantly only in patients with restored SR and not in patients with persistent AF. This interesting finding, indicating a better working capacity or exercise tolerance in these patients though not documented by $\dot{\mathrm{V}}_{2}$, has been also observed in a previous study. ${ }^{23}$ A significant decrease of peak heart rate was also found only in patients with restored SR after surgery. Thus, restored SR may be advantageous in achieving a larger maximum work load at a lower heart rate.

\section{Mechanism of improvement in exercise capacity}

Although previous studies ${ }^{17}{ }^{18}$ have shown improved exercise capacity after the maze procedure combined with mitral valve surgery, the precise mechanism has not been well elucidated.
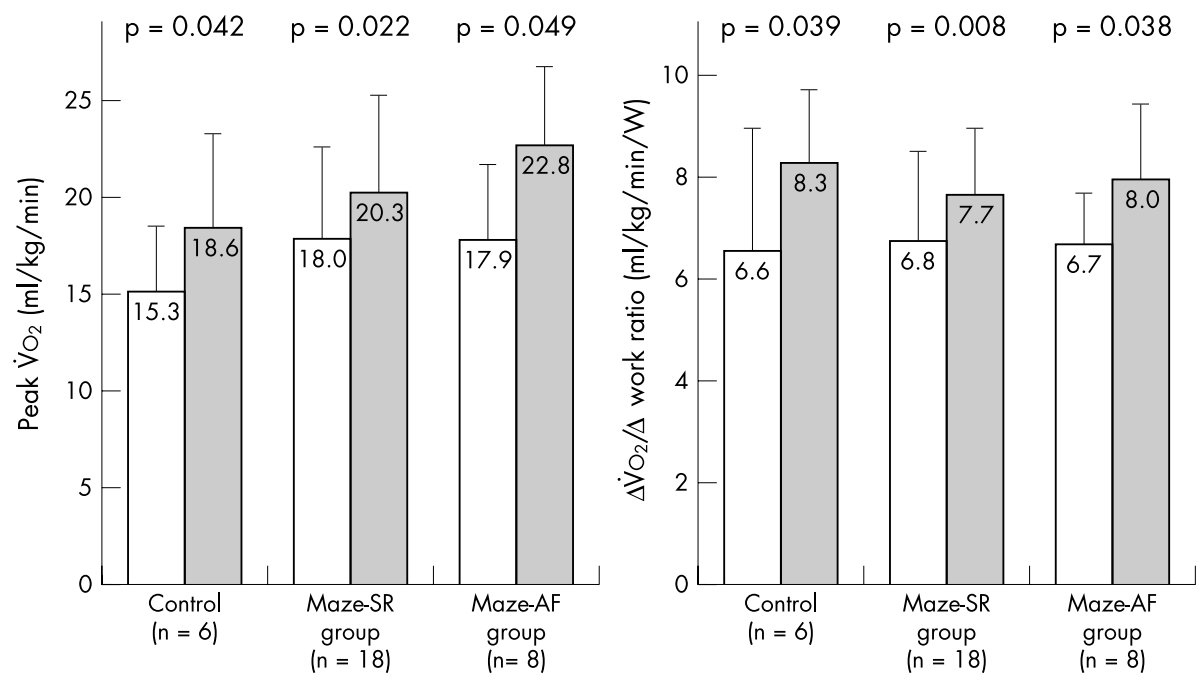

Figure 1. Comparison of peak oxygen uptake $\left(\mathrm{V}_{2}\right)$ (left panel) and ratio of $\Delta \mathrm{VO}_{2}$ to $\Delta$ work (right panel) between the control, maze-sinus rhythm (SR), and maze-atrial fibrillation (AF) groups before (open bars) and after (grey bars) surgery. 


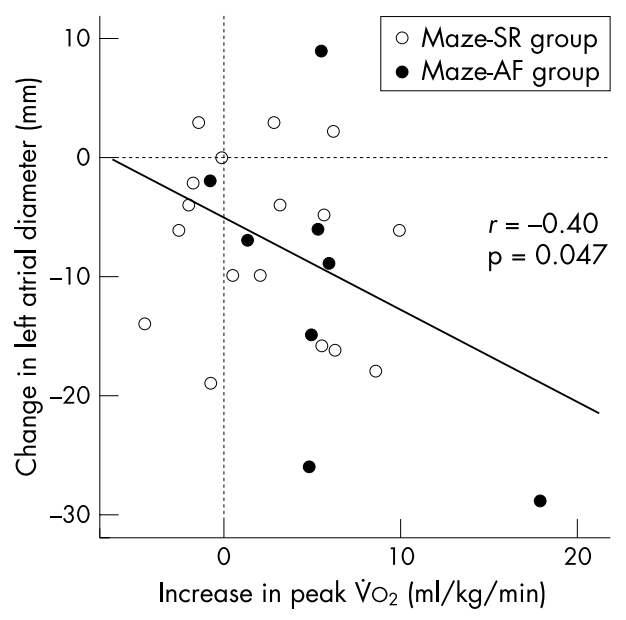

Figure 2 Correlation between increases in peak $\dot{\mathrm{V}}_{2}$ and changes in left atrial diameter after surgery. Open circles, maze-SR group; solid circles, maze-AF group.

Several possible mechanisms may account for that finding. Firstly, the reduction in pulmonary venous pressures at rest and during exercise after mitral valve surgery has been known ${ }^{2}$ and it may contribute to the improvement in exercise capacity by decreasing lung interstitial fluid accumulation and lung compliance. Triposkiadis and colleagues ${ }^{3}$ found a significant relation between peak $\dot{\mathrm{V}}_{2}$ after mitral valve replacement and the ratio of right ventricular acceleration to ejection time, an index of mean pulmonary artery pressure. ${ }^{24}$ Secondly, Tanabe and associates ${ }^{25}$ showed a decrease in excessive exercise ventilation due to reduced physiological dead space after balloon mitral valvoplasty and an association with improved exercise capacity. Further, this ventilatory improvement has been related to the amelioration of postexercise exertional dyspnoea after balloon mitral valvoplasty. ${ }^{27}$ The relation also has been observed after mitral valve surgery. ${ }^{7}$ Thus, the decrease in excessive exercise ventilation, which was not assessed in this study, leads to an increase in physical activity through relief of exertional dyspnoea and consequently may improve exercise capacity. We speculate that, although restoration of SR by the maze procedure is advantageous, it may not equal the dramatically improved haemodynamic ${ }^{2}$ and ventilatory function ${ }^{76}$ after mitral valve surgery. The fact that exercise capacity of patients with residual valve regurgitation did not improve significantly may support this speculation.

We found a significant relation between improved peak $\dot{\mathrm{V}}_{2}$ and reduced LA diameter. A similar finding has been reported following mitral valve replacement for mitral stenosis. ${ }^{4}$ The reduction of LA diameter after mitral valve surgery may lead to improved respiratory function by decreasing bronchopulmonary compression, as is seen after the LA plication procedure in patients with giant LA. ${ }^{28}$ Another possible explanation is that a reduced LA diameter has the potential to reduce LA wall tension and increase LA contractility, as in the LV after partial LV ventriculectomy. ${ }^{29}$ Augmentation of LA contractility may facilitate a reduction of pulmonary artery pressure and improvement in right ventricular function. However, the precise mechanism underlying this relation has been unclear.

\section{Study limitations}

This study was retrospective and had several limitations. Firstly, the small number of patients in each subgroup limited the power of the conclusions. Secondly, the cardiopulmonary exercise test and ultrasound examination were not performed on the same day. Thirdly, although the proportion of mitral valve disease was similar in the three groups, various mitral valve diseases were present. Consequently, large prospective studies will be necessary to determine whether the maze procedure contributes to an improvement in exercise capacity in patients with uniform mitral valve disease (for example, pure mitral stenosis or pure mitral regurgitation). Lastly, because we had no additional pulmonary vein flow data and LA volume measurements, quantification of LA systolic function was not feasible. Thus, the possibility of LA systolic dysfunction in the patients with successfully restored SR after the maze procedure cannot be excluded. The absence of invasive pulmonary pressure measurement was also a problem.

\section{Conclusions and clinical implications}

Our findings suggest that improvement in exercise capacity after the maze procedure combined with mitral valve surgery may not be caused by restored SR and atrial contraction but may be at least partly related to the reduction of LA size. Regarding the improvement in exercise capacity in patients with mitral valve disease, the advantage of restoration of SR by the maze procedure, which has been observed in patients with lone $A F,{ }^{19}$ may not be clear due to the dramatic changes in haemodynamic factors ${ }^{2}$ and ventilatory function $^{726}$ after mitral valve surgery. However, the regularised rhythm and adequate sinoatrial conduction with restored atrial function after the maze procedure may contribute to an increase in quality of $\operatorname{life}^{30}$ and a larger maximum work load. ${ }^{23}$

LA dimension after the maze procedure has been known to decrease significantly and did not change during the follow up period..$^{15} 16^{20}$ We speculate that extensive suturing of the LA wall may contribute to the reduction of chamber size and prevent LA redilatation after the maze procedure. Kawaguchi and colleagues ${ }^{31}$ reported a favourable effect of reduced LA size on restoration of SR after the maze procedure. Reduced LA size combined with the maze procedure has been shown to diminish blood stasis in the $\mathrm{LA}^{32}$ and may reduce the incidence of stroke after the maze procedure, which has been reported recently. ${ }^{33}$ Prospective studies should be planned to investigate the effectiveness of reduced LA size in restoring SR and preventing thromboembolism after the maze procedure.

\section{ACKNOWLEDGEMENTS}

This study was supported in part by a Research Grant for Cardiovascular Diseases from the Ministry of Health, Labour and Welfare of Japan, Tokyo, Japan. This study was presented in part at the 48th annual scientific sessions of the American College of Cardiology, New Orleans, Louisiana, March 1999.

\section{Authors' affiliations}

S Yuda, S Nakatani, T Satoh, Y Goto, M Yamagishi, K Miyatake, Divisions of Cardiology, National Cardiovascular Centre, Osaka, Japan Y Kosakai, K Bando, S Kitamura, Cardiovascular Surgery, National Cardiovascular Centre, Osaka, Japan

Dr Yuda is now at the Second Department of Internal Medicine, Sapporo Medical University of School of Medicine, Sapporo, Japan. Dr Kosakai is now at Takarazuka Municipal Hospital, Hyogo, Japan

\section{REFERENCES}

1 Gohlke-Bärwolf C, Gohlke H, Samek L, et al. Exercise tolerance and working capacity after valve replacement. J Heart Valve Dis 1992;1:189-95.

2 McKay CR, Kawanishi DT, Kotlewski A, et al. Improvement in exercise capacity and exercise hemodynamics 3 months after double-balloon, catheter balloon valvuloplasty treatment of patients with symptomatic mitral stenosis. Circulation 1988;77:1013-21.

3 Triposkiadis F, Trikas A, Tentolouris K, et al. Effects of atrial fibrillation on exercise capacity in mitral stenosis. Am J Cardiol 1995;76:282-6. 
4 Trikas A, Papadopoulos P, Triposkiadis F, et al. Factors affecting the postoperative exercise capacity of patients with mitral stenosis and aortic regurgitation. Cardiology 1994;85:201-6

5 Groves PH, Lewis NP, Ikram S, et al. Reduced exercise capacity in patients with tricuspid regurgitation after successful mitral valve replacement for rheumatic mitral valve disease. Br Heart J 1991;66:295-301.

6 Toyomasu K, Nishiyama Y, Yoshida N, et al. Physical training in patients with valvular heart disease after surgery. Jpn Circ J 1990;54:1451-8.

7 Rhodes KM, Evemy K, Nariman S, et al. Effects of mitral valve surgery on static lung function and exercise performance. Thorax 1985:40:107-12.

8 Barlow CW, Long JEH, Brown G, et al. Exercise capacity and skeletal muscle structure and function before and after balloon mitral valvuloplasty. Am J Cardiol 1995;76:684-8.

9 Yasu T, Katsuki T, Ohmura N, et al. Delayed improvement in skeletal muscle metabolism and exercise capacity in patients with mitral stenosis following immediate hemodynamic amelioration by percutaneous transvenous mitral commissurotomy. Am J Cardiol 1996;77:492-7

10 Cohen-Solal A, Aupetit JF, Dahan M, et al. Peak oxygen uptake during exercise in mitral stenosis with sinus rhythm or atrial fibrillation: lack of correlation with valve area. A study in 70 patients. Eur Heart $J$ 1994; 15:37-44.

11 Tamai J, Yoshioka T, Yasuda S, et al. Increase in peak oxygen uptake by restoration of atrial contraction in patients after percutaneous transvenous mitral commissurotomy. J Heart Valve Dis 1993;2:623-8.

12 Cox JL, Schuessler RB, D'Agostino HJ Jr, et al. The surgical treatment of atrial fibrillation. III. Development of a definitive surgical procedure. J Thorac Cardiovasc Surg 1991;101:569-83.

13 Kosakai Y, Kawaguchi AT, Isobe F, et al. Cox maze procedure for chronic atrial fibrillation associated with mitral valve disease. J Thorac Cardiovasc Surg 1994; 108:1049-55.

14 Cox JL, Boineau JP, Schuessler RB, et al. Five-year experience with the maze procedure for atrial fibrillation. Ann Thorac Surg 1993:56:814-24.

15 Kawaguchi AT, Kosakai Y, Sasako Y, et al. Risks and benefits of combined maze procedure for atrial fibrillation associated with organic heart disease. J Am Coll Cardiol 1996;28:985-90.

16 Yuda S, Nakatani S, Kosakai Y, et al. Long-term follow-up of atrial contraction after the maze procedure in patients with mitral valve disease. J Am Coll Cardiol 2001;37:1622-7.

17 Tamai J, Kosakai Y, Yoshioka T, et al. Delayed improvement in exercise capacity with restoration of sinoatrial node response in patients after combined treatment with surgical repair for organic heart disease and the maze procedure for atrial fibrillation. Circulation 1995:91:2392-9.

18 Ueshima K, Hashimoto K, Chiba M, et al. Recovery of atrial function combined treatment with surgical repair for organic heart disease and maze procedure for atrial fibrillation. J Thorac Cardiovasc Surg 1997;1 13:214-5.
19 Jessurun ER, van Hamel NM, Defauw JAMT, et al. Results of maze surgery for lone paroxysmal atrial fibrillation. Circulation 2000;101:1559-67.

20 Yuda S, Nakatani S, Isobe F, et al. Comparative efficacy of the maze procedure for restoration of atrial contraction in patients with and withou giant left atrium associated with mitral valve disease. J Am Coll Cardiol 1998;31:1097-102.

21 Oh JK, Seward JB, Tajik AJ. Pulmonary hypertension. In: Weinberg RW, Simmons LA, eds. The echo manual, 2nd ed. Philadelphia: Lippincott-Raven, 1999:215-22

22 Solal AC, Chabernaud JM, Gourgon R. Comparison of oxygen uptake during bicycle exercise in patients with chronic heart failure and in normal subjects. J Am Coll Cardiol 1990;16:80-5.

23 Deneke T, Khargi K, Grewe PH, et al. Efficacy of an additional MAZE procedure using cooled-tip radiofrequency ablation in patients with chronic atrial fibrillation and mitral valve disease. Eur Heart J 2002;23:558-66.

24 Kitabatake A, Inoue M, Asao M, et al. Noninvasive evaluation of pulmonary hypertension by a pulsed Doppler technique. Circulation 1983;68:302-9.

25 Tanabe $Y$, Suzuki M, Takahashi M, et al. Acute effect of percutaneous transvenous mitral commissurotomy on ventilatory and hemodynamic responses to exercise. Pathophysiological basis for early symptomatic improvement. Circulation 1993;88:1770-8.

26 Tanabe Y, Oshima M, Suzuki M, et al. Determinants of delayed improvement in exercise capacity after percutaneous transvenous mitral commissurotomy. Am Heart J 2000; 139:889-94.

27 Tanabe $Y$, Ito $M$, Hosaka $Y$, et al. Effect of percutaneous transvenous mitral commissurotomy on postexercise breathlessness as determined by ventilation during recovery from constant workload exercise. Am J Cardiol 1998:82:1132-5.

28 Kawazoe K, Beppu S, Takahara Y, et al. Surgical treatment of giant left atrium combined with mitral valvular disease. Plication procedure for reduction of compression to the left ventricle, bronchus, and pulmonary parenchyma. J Thorac Cardiovasc Surg 1983;85:885-92.

29 Batista RJV, Verde J, Nery P, et al. Partial left ventriculectomy to treat endstage heart disease. Ann Thorac Surg 1997;64:634-8.

30 Lönnerholm S, Blömstorm P, Nilsson L, et al. Effects of maze operation on health-related quality of life in patients with atrial fibrillation. Circulation 2000;101:2607-11.

31 Kawaguchi AT, Kosakai Y, Isobe F, et al. Factors affecting rhythm after the maze procedure for atrial fibrillation. Circulation 1996;94(suppl II):II139-42.

32 Nasu M, Sato Y, Tashiro A, et al. Blood stasis in large left atrium after maze procedure [abstract]. Circulation 1997:96:1382.

33 Cox JL, Ad N, Palazzo T. Impact of the maze procedure on the stroke rate in patients with atrial fibrillation. J Thorac Cardiovasc Surg $1999 ; 118: 833-40$

\section{FROM BMJ JOURNALS}

\section{Atrial septostomy in the treatment of severe pulmonary arterial hypertension}

F Reichenberger, J Pepke-Zaba, K McNeil, J Parameshwar, L M Shapiro

Please visit the Heartwebsite [www.heartinl. com] for a link to the full text of this article.
Background: Atrial septostomy (AS) may improve symptoms and haemodynamics in patients with severe pulmonary arterial hypertension (PAH).

Methods: Twenty AS performed in 17 patients with severe progressive PAH ( 13 primary pulmonary hypertension, two collagen vascular disease, one thromboembolic disease, one vaso-occlusive disease) were analysed. Seven patients were in NYHA class III and 10 in NYHA IV. Fifteen patients were on long term prostanoid treatment. AS was performed under fluoroscopy using graded balloon technique.

Results: AS improved clinical symptoms and increased the cardiac index from 1.8 to $2.2 \mathrm{l} /$ $\mathrm{min} / \mathrm{m}^{2}$ and systemic oxygen transport from 263.2 to $329.6 \mathrm{ml} / \mathrm{min} / \mathrm{m}^{2}(\mathrm{p}<0.001)$. Procedure related complications included one non-fatal atrial puncture and one unsuccessful septal puncture. Four patients died within 1 week of surgery from uncontrolled tachyarrhythmia $(\mathrm{n}=1)$, severe hypoxaemia $(\mathrm{n}=1)$, and multiorgan failure $(\mathrm{n}=2)$. One further patient died after voluntarily discontinuing renal dialysis. Twelve patients are alive 5-17 months after the operation with five patients undergoing heart-lung transplantation. There were no differences in haemodynamic and functional parameters between the non-survivors and the mid term survivors. However, the non-survivors were significantly older ( $52 \mathrm{v} 36$ years, $\mathrm{p}<0.01)$ and had a significantly lower creatinine clearance rate $(70 \mathrm{ml} / \mathrm{min}$ v $48 \mathrm{ml} / \mathrm{min}$, $\mathrm{p}<0.05$ ).

Conclusion: Atrial septostomy improves clinical symptoms, cardiac index, and systemic oxygen transport and has the potential to influence the prognosis in selected cases of severe PAH.

A Thorax 2003;58:797-800. 